\title{
Multiphysical characterization of FSW of aluminum electrical busbars with copper ends
}

\author{
Dagur Ólafsson $^{1,2} \cdot$ Pedro Vilaça $^{1}$ (iD $\cdot$ Jussi Vesanko ${ }^{3}$
}

Received: 30 June 2019 / Accepted: 5 October 2019/Published online: 4 November 2019

(C) The Author(s) 2019

\begin{abstract}
This work investigates the benefits of having an aluminum (Al) busbar with welded copper $(\mathrm{Cu})$ ends, and evaluates the force relaxation phenomena of a pre-loaded bolt joint on $\mathrm{Cu}$ versus $\mathrm{Al}$, under cyclic thermal loading. The results show a force relaxation rate $50 \%$ lower in the $\mathrm{Cu}$-bolted joint compared with the one in $\mathrm{Al}$. The core of this research is the weldability analysis of Al-Cu butt joints made by friction stir welding (FSW). The materials are AA1050 H14/24 and Cu OF 04 with thickness of 6 $\mathrm{mm}$. Temperature monitoring during the FSW cycle emphasize how heat generation depends mostly on local internal viscoplastic deformation. Tensile, bending, and microhardness tests were used to establish the mechanical properties. Optical microscope and scanning electron microscopy were used to characterize the microstructure. Joining mechanisms in the weld were investigated using energy-dispersive X-ray spectroscopy. The FSW resulted in $85 \%$ tensile strength efficiency compared to the Al base material, and $97 \%$ electrical conductivity efficiency compared to an ideal bimetallic component made of the same materials with no contact resistance. Electrical resistance of the FSW is 200 times lower than the electrical contact resistance between the Al-Cu materials while under high compressive force.
\end{abstract}

Keywords Friction stir welding - Aluminum - Copper - Busbar - Electrical resistance · Temperature · Microstructure · Intermetallic compounds $\cdot$ Mechanical properties

\section{Introduction}

Various industries constantly strive to improve their competitiveness, with higher performance products made with efficient processes with low environmental impact. Most of the developments are supported by material optimization demanding advanced solution for manufacturing, where joining of dissimilar engineering materials is typically the most challenging process. On this scope, the friction stir welding (FSW) [1] is a modern solid-state material joining technique, which opens up possibilities in manufacturing joints of dissimilar materials that are difficult, or even impossible, to do with conventional fusion welding methods. Due to high forces,

Pedro Vilaça

pedro.vilaca@aalto.fi

1 Department of Mechanical Engineering, School of Engineering, Aalto University, Espoo, Finland

2 Innovation Center Iceland, Reykjavík, Iceland

3 Promeco Oy, Kankaanpää, Finland the process is fully mechanized enabling high productivity for high production series, lowering the depended on skill requirements and thus cost of operation [2]. In FSW, the heat is mostly generated by friction dissipation during the internal plastic deformation, and thus the materials do not reach their melting temperatures as the local heat generation is reduced to zero as the increasing temperature tends to melting [3,4]. This means that when FSW of dissimilar materials, the local temperature is the one enabling the local viscoplastic deformation imposed by the rigid tool, clamping conditions, and process parameters. This same phenomenon is later emphasized in this paper, based on the results from the monitoring of the temperatures during the FSW of the Al-Cu joints. Good quality FSW bimetallic joints are now feasible for $\mathrm{Al}$ to steel [5-7] and $\mathrm{Al}$ to $\mathrm{Cu}$ [8]. Avoiding common problems associated with fusion welding of dissimilar metals, such as mismatch of fusion temperature, formation of extensive brittle intermetallic compounds (IMC's), gas solubility, and high distortion, and residual stress [2], the FSW opened up new possibilities in the design optimization and manufacturing of various products. In particular, electrical applications such as the busbars can get significant benefits from combining cheaper and lighter 
material, such as $\mathrm{Al}$, with $\mathrm{Cu}$ that has lower electrical resistance, with more stable mechanical properties and corrosion resistance in a wider temperature range.

Busbars are conductive strips or bars used for short distance high current power transference. In recent years, the material choice for busbars has been changing from $\mathrm{Cu}$ to Al. This is due to the lower price and higher conductivity of the $\mathrm{Al}$ when considered on a per kilogram basis [9]. The decrease in the direct cost and weight of the busbar is attractive, but perhaps short-sighted. High clamping forces are required for busbar connections to minimize the contact resistance between the busbars and other components [10]. These high forces, along with the temperature, change the connection experience, while in operation slowly deform the pressed material, which in turn lowers the clamping forces. High thermal expansion and oxidation of the $\mathrm{Al}$ further degrade the electrical connection [11]. To avoid component failure, the connection therefore needs to be retightened periodically. This results in maintenance costs, and increases the life cycle price of the Al busbar.

Elevated temperatures affect $\mathrm{Al}$ alloys commonly used for busbars such as AA6101-T4 more than high conductive $\mathrm{Cu}$ alloys like $\mathrm{Cu}-\mathrm{OF}[12,13]$. The thermal expansion coefficient is also higher for $\mathrm{Al}$ than for $\mathrm{Cu}$ [14]. These differences between the two materials might explain the higher maintenance associated with $\mathrm{Al}$ busbars. A potential solution to this problem is to use bimetallic busbars made from both materials, $\mathrm{Al}$ and $\mathrm{Cu}$. A busbar mainly composed of $\mathrm{Al}$ but with $\mathrm{Cu}$ ends has the advantage of being cheaper and lighter than a monolithic $\mathrm{Cu}$ busbar but avoids the increase in maintenance cost associated with monolithic $\mathrm{Al}$ busbars. Additionally, $\mathrm{Cu}$ ends are more suitable for clamped connections with other $\mathrm{Cu}$ parts in an electrical system than $\mathrm{Al} / \mathrm{Cu}$ - or $\mathrm{Al} / \mathrm{Al}$-bolted connections $[15,16]$. For this solution to be viable, these bimetallic busbars need to be manufactured efficiently.

Difference in fusion temperatures, as between $\mathrm{Cu}$ and $\mathrm{Al}$, is not a problem for the FSW, but several other issues remain contributing for the $\mathrm{Al}-\mathrm{Cu}$ made by FSW to be a challenging joint, still demanding research on the influence of the FSW conditions on the joint properties.
Among these issues are the different deformation behaviors, formation of IMCs even at low temperatures, and differences in physical properties and their evolution with temperature, promoting asymmetry in the flow of material and heat during the FSW [17]. The IMCs are defined as solid phases containing two or more metallic elements, with optionally one or more non-metallic elements, whose crystal structure differs from that of the other constituents [18]. They are generally very stable, brittle, and with a high fusion temperature, causing a problem in the welding of dissimilar materials, both in fusion and solid-state welding. In fusion welding, they are generally formed during the solidification of the welding pool. In FSW, they form under high pressures and intense plastic deformation [19] under the heating of the welded joint. In fusion welding of dissimilar materials, the amount of intermetallic compounds is so that it compromises the weld in almost every case and renders the welding method useless for many material combinations such as $\mathrm{Al}$ and $\mathrm{Cu}$ [20].

In this work, the difference in force relaxation rates between $\mathrm{Cu}-\mathrm{OF}-04$ and strain-hardened AA6101-T4 under a $40 \mathrm{kN}$ clamping force from a bolt while under cyclic thermal loading, simulating a busbar connection while in operation, is investigated to learn about the effective level of benefit in producing Al-busbar with $\mathrm{Cu}$ ends, as represented in Fig. 1. The weldability analysis focuses on the FSW of the bimetallic joint between plates with thickness of $6 \mathrm{~mm}$ made of AA1050-H14/24 and Cu-OF-04. The Al material in the FSW joint was selected to maximize the electrical conductivity (where $\sigma_{\mathrm{Cu}-\mathrm{OF}} \cong 100 \%$ IACS; $\sigma_{\mathrm{AA} 1050} \cong 61 \%$ IACS; and $\sigma_{\mathrm{AA} 6101} \cong 43 \%$ IACS), because there is no need for higher mechanical resistance, as provided by AA6101-T4, when the busbar ends are made of $\mathrm{Cu}$. During the FSW, the temperatures were monitored. Tensile, bending, and microhardness tests were used to establish the mechanical properties. Optical microscope and scanning electron microscope were used to investigate the microstructure. The electrical resistance of the $\mathrm{Al}-\mathrm{Cu}$ weld and contacting $\mathrm{Al}-\mathrm{Cu}$ components under different clamping force levels was assessed using a microhmmeter.

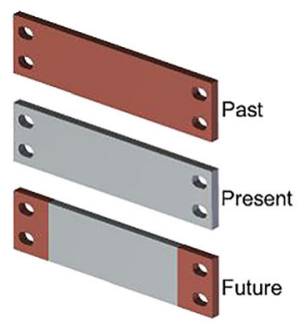

a)

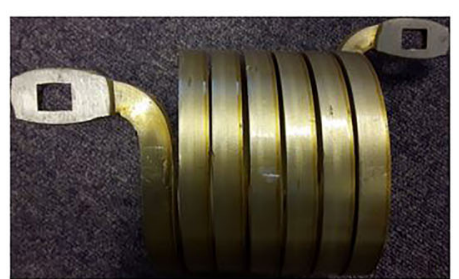

b)

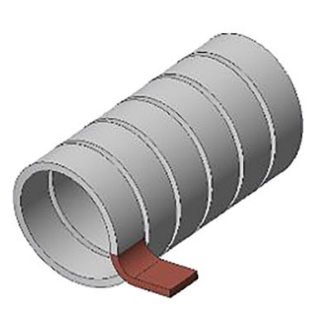

c)

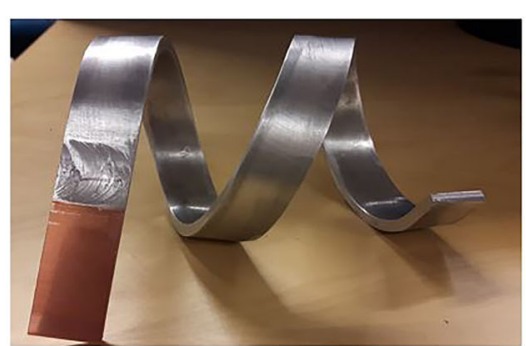

d)

Fig. 1 Scope and concept of the aluminum-based busbar (Al-busbar) with welded copper $(\mathrm{Cu})$ ends: (a) evolution of the material selection for the busbars to link electrical power systems; (b) an example of an

industrial busbar made of aluminum; (c) schematic concept of the busbar with a welded copper end; (d) implementation with the FSW conditions investigated in this research work 


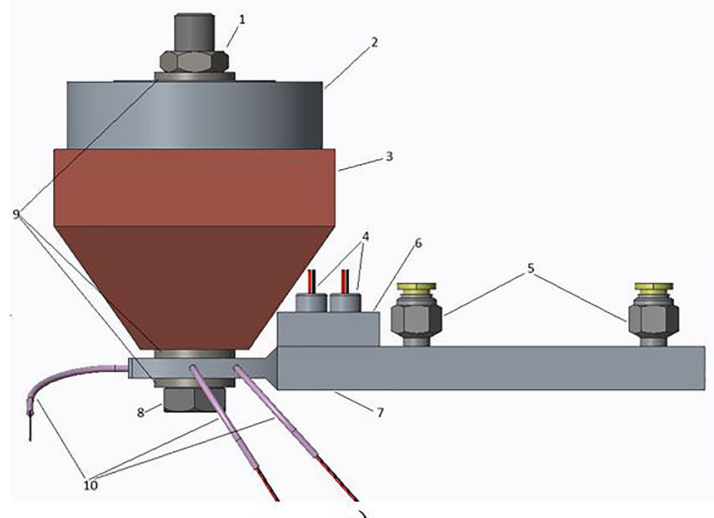

a)

Fig. 2 Experimental setup of the clamping force relaxation experiment: (a) schematic representation of the components where 1, 8, and 9 are M12 nut, bolt, and stainless steel washers, respectively; 2, load cell; 3, load pyramid; 4 and 6 , cartridge heaters and socket, respectively; 5, cooling

\section{Evaluation of the clamping force relaxation}

\subsection{Experimental conditions and methods}

The experimental setup, presented in Fig. 2, is made of several parts. A strain-gauge load cell and the busbar end are clamped together between a bolt and a nut, separated by stainless steel washers and a load pyramid, which transfers the load from the larger load cell to the small end of the bus bar. Behind the flattened mounting end of the bus bar, cartridge heaters are placed and an internal cooling channel was made. To monitor the thermal cycles in the investigated zone, three K-type thermocouple wires are welded to the flattened end part of both the $\mathrm{Cu}$ and $\mathrm{Al}$ testing specimens. These thermocouples are positioned near the edge of the flattened end part, around and equidistant from the clamping system. Three thermocouples are used to be sure about the uniform thermal distribution in the zone under investigation and for matter of redundancy of the information. The flattened part of the $\mathrm{Cu}$ component is

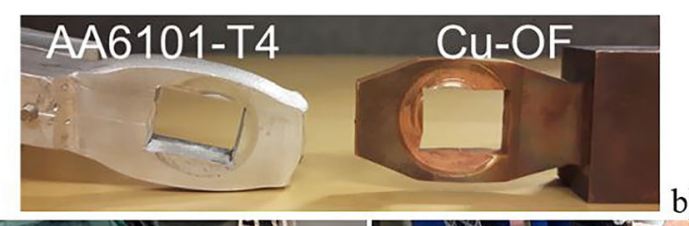

b)

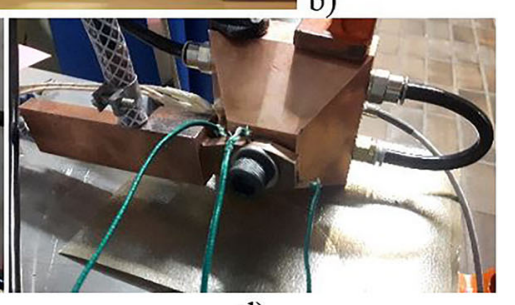

d)

connectors; 7, busbar end; 10, thermocouples. (b) Tested busbar ends made of AA6101-T4 and Cu-OF-04. (c), (d) Testing apparatus for the AA6101-T4 and Cu-OF-04, respectively

machined with an $\mathrm{HV} 05_{\mathrm{Cu}-\mathrm{OF}} \cong 88$; the flattened part of the $\mathrm{Al}$ component is forged reaching an $\mathrm{HV} 05_{\mathrm{AA} 6101 \text { FlattenedEnd }} \cong$ 90, from the original base material hardness of $\mathrm{HV} 05_{\mathrm{AA} 6101-}$ $\mathrm{T} 4 \cong 60$.

The test was controlled and conducted as follows: the force and temperature monitoring is activated and the data is sampled and logged with certain sampling frequencies, $\mathrm{f}_{\mathrm{F}}$ and $\mathrm{f}_{\mathrm{T}}$. The bolt is preloaded with a certain force, $\mathrm{F}_{0}$, and the cooling flow is turned on. Then an iterative cycle begins. The heaters are turned on for a certain amount of time, $\Delta \mathrm{t}_{\mathrm{Hot}}$, allowing the temperature of the busbar end to reach $\mathrm{T}_{\mathrm{Hot}}$. Then, the heaters are turned off for a certain amount of time, $\Delta \mathrm{t}_{\text {Cold }}$, allowing the temperature to reach $\mathrm{T}_{\text {Cold }}$. If either the number of cycles has reached a certain maximum, $\mathrm{N}_{\max }$, or the force is under a certain minimum, $\mathrm{F}_{\text {min }}$, the cooling flow is turned off, the test is stopped, and the data is analyzed. Otherwise, the process goes through another iterative cycle. The flowchart in Fig. 3 further depicts the test protocol. Tests were run for each material using a peak temperature of $190 \pm 5^{\circ} \mathrm{C}$. The peak

Fig. 3 Test protocol for the clamping force relaxation experiment

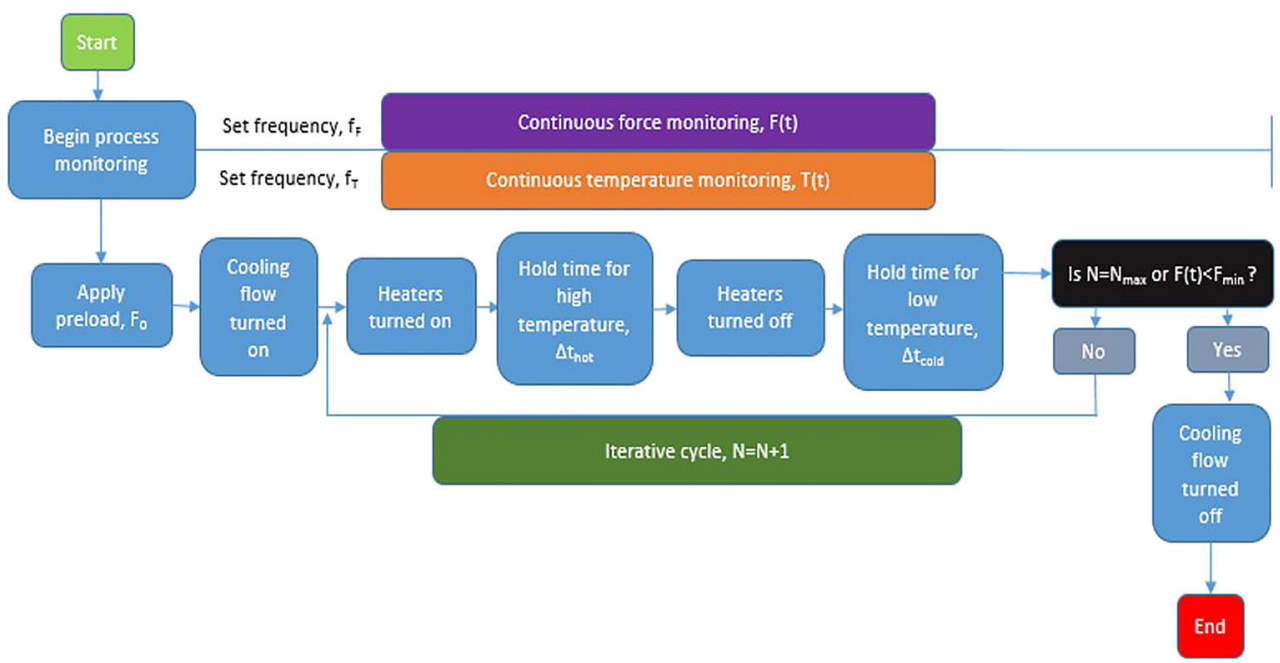


Table 1 Summary of the results of the clamping force relaxation test detailing the clamping force at different cycles as well as the average rate in clamping force between cycles 100-200 for each material

\begin{tabular}{llccc}
\hline$T_{\max } / \Delta T$ & Material & $F_{@ 300 \text { cycles }}$ & $F_{@ 800 \text { cycles }}$ & $\Delta F /$ cycle @ 100-200 cycles \\
\hline $190{ }^{\circ} \mathrm{C} / 60{ }^{\circ} \mathrm{C}$ & Cu-OF-04 & $33.8 \mathrm{kN}$ & $33.2 \mathrm{kN}$ & $-4.2 \mathrm{~N}$ \\
& AA6101-T4 & $26.5 \mathrm{kN}$ & $25.3 \mathrm{kN}$ & $-8.1 \mathrm{~N}$ \\
\hline
\end{tabular}

temperature considered is the temperature measured by the thermocouple closest to the source of the heat, i.e., the cartridge heaters. The sampling frequencies $\mathrm{f}_{\mathrm{F}}$ and $\mathrm{f}_{\mathrm{T}}$ were both 1 $\mathrm{Hz}$. The heating cycle was so that the heaters were on for $50 \mathrm{~s}$ and off for $20 \mathrm{~s}$. Both experiments used a preload force of 40 $\mathrm{kN}$. The contact surface area between the washers and the busbar ends was estimated to be $230 \mathrm{~mm}^{2}$; thus, the initial contact pressure is estimated as $170 \mathrm{MPa}$.

\subsection{Results}

The clamping force relaxes at a higher rate for AA6101-T4 than for $\mathrm{Cu}-\mathrm{OF}-04$. From the original $40 \mathrm{kN}$, the clamping force in the Al lowers to $25.2 \mathrm{kN}$ after 881 cycles while the force on the $\mathrm{Cu}$ lowers to $32.9 \mathrm{kN}$ after 1236 cycles. Table 1 depicts the clamping force in the tests at 300 and at 800 cycles as well as the average rate of drop of the clamping force per cycle between 100 and 200 cycles. The reference rate of the clamping force relaxation measured was $\Delta \mathrm{F} /$ cycle $_{@ 100-200 \text { cycles }}=-4.2 \mathrm{~N}$ for the $\mathrm{Cu}-\mathrm{OF}-04$ and $\Delta \mathrm{F} /$ cycle $_{@ 100-200 \text { cycles }}=-8.1 \mathrm{~N}$ for the AA6101-T4. From Fig. 4, where it is presented the evolution of the clamping force along the whole thermal fatigue test, it is possible to conclude that the relaxation rates of the clamping force are higher at start of the test, when higher clamping forces are present, and that the relation between the relaxation rates exhibited by the $\mathrm{Al}$ and the $\mathrm{Cu}$ end busbar components remains essentially constant during the whole test at about the double.

Plot of the clamping force versus time for both the AA6101-T4 and the Cu-OF-04. The detail focuses on the period of about $13 \mathrm{~min}$, between the 50th and the 60th cycles. The relaxation rates exhibited by the $\mathrm{Al}$ component are about the double of the $\mathrm{Cu}$ end busbar component. The relaxation rates of the clamping force are higher at start of the test, when higher clamping forces are present. This phenomenon is probably induced by differences in yield strength at elevated temperatures and thermal expansion coefficients between the Aland $\mathrm{Cu}$-based materials. The AA6061 is probably overaged and loses its mechanical resistance in this range of temperature operation.

The threshold for preventive maintenance of the bolted clamping force will depend on the operation conditions and inherent interfacial electrical resistance for different levels of clamping force. These resistance values will be presented later in this paper. But immediately, whatever are the threshold criteria for maintenance operation, $\mathrm{Cu}$ ends for the busbar, will have a very significant benefit in increasing the preventive maintenance interval and overall safety of the electrical system operation.
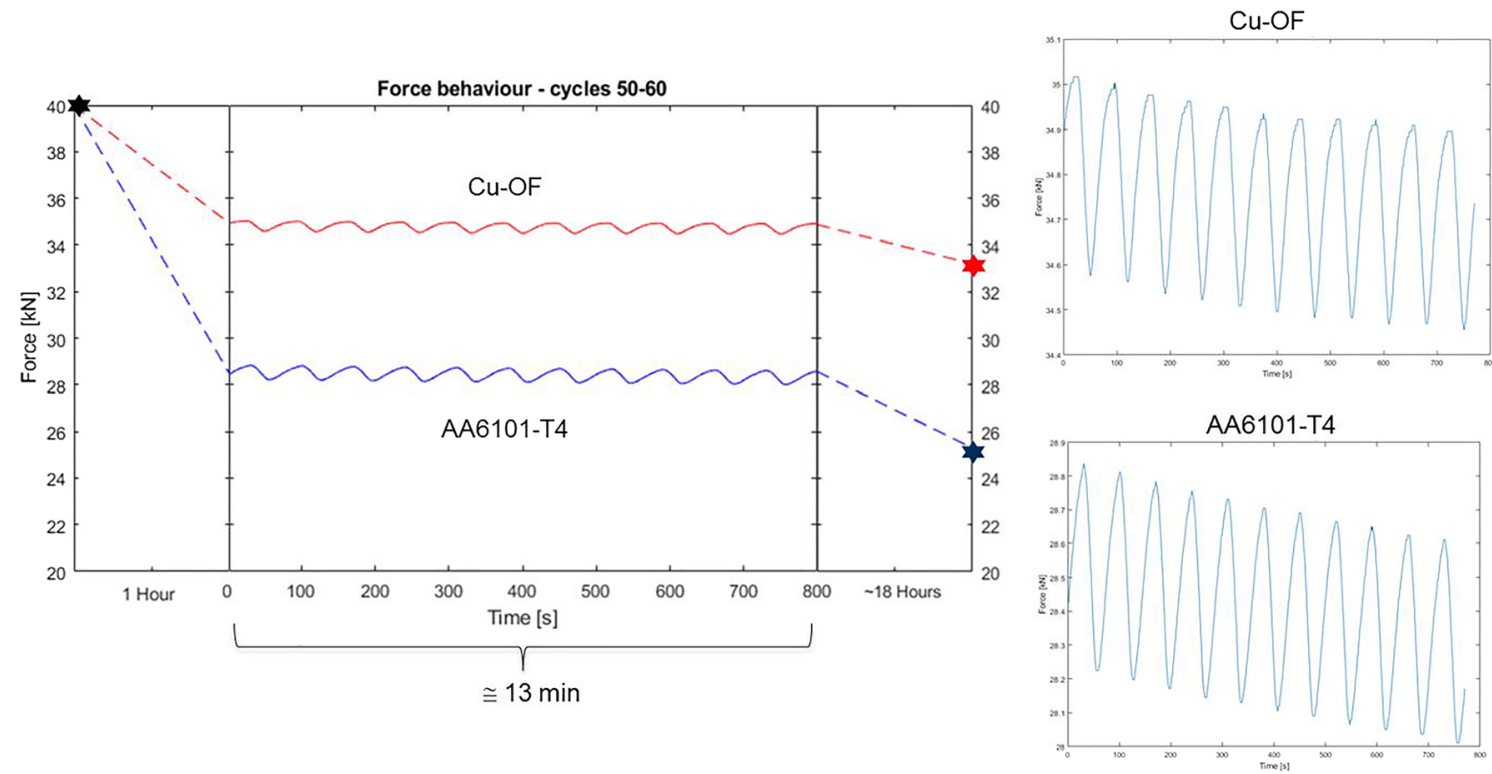

Fig. 4 Plot of the clamping force versus time for both the AA6101-T4 and the $\mathrm{Cu}-\mathrm{OF}-04$. The detail focuses on the period of about $13 \mathrm{~min}$, between the 50 th and the 60 th cycles. The relaxation rates exhibited by the $\mathrm{Al}$ component are about the double of the busbar $\mathrm{Cu}$ end component. The relaxation rates of the clamping force are higher at start of the test, when higher clamping forces are present 


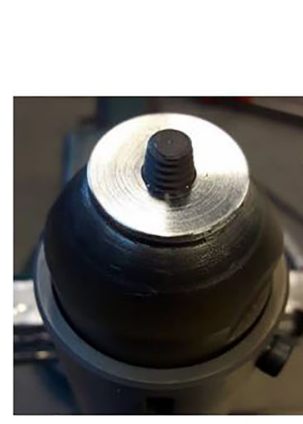

a)

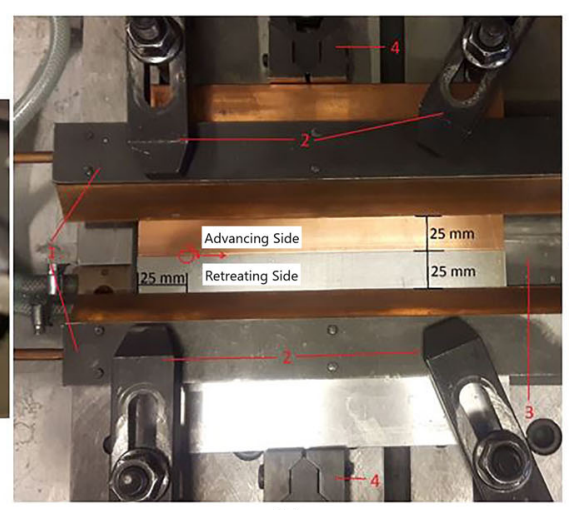

b)

Fig. 5 The FSW welding conditions: (a) tool with a concave shoulder and taper LH-threaded probe; (b) the clamping system with the (1) refrigerated $\mathrm{Cu}$ clamping bars and (2) steel clamps, (3) refrigerated baking anvil,

\section{Weldability analysis of the Al-Cu plate system}

\subsection{Experimental conditions and methods}

Base materials The aluminum selected for the busbars was a rolled plate of AA1050-H14/H24, which is a highly conductive $\left(\sigma_{\mathrm{AA} 1050} \cong 61 \%\right.$ IACS $)$ and commercial pure aluminum material $(\mathrm{Al} \geq 99.5 \%)$. The $\mathrm{Cu}$ plate chosen is a high-purity, oxygen-free, non-phosphorus-deoxidized $\mathrm{Cu}$ alloy that does not contain any vacuum-evaporating elements. Generally, it is simply known as oxygen-free copper or $\mathrm{Cu}-\mathrm{OF}\left(\sigma_{\mathrm{Cu}-\mathrm{OF}} \cong\right.$ $100 \%$ IACS). The particular classification used during this work was $\mathrm{Cu}-\mathrm{OF}-04$. The thickness of all plates was $6 \mathrm{~mm}$. The plates were prepared to be welded along the rolling direction (RD) and were cut with dimensions $250 \mathrm{~mm}(\mathrm{RD}) \times 60$ $\mathrm{mm}$. The hardness measured at top surface for the $\mathrm{Al}$ and $\mathrm{Cu}$ plates were $\mathrm{HV} 05_{\mathrm{AA} 1050} \cong 40$ and $\mathrm{HV} 05_{\mathrm{Cu}-\mathrm{OF}} \cong 88$, respectively.

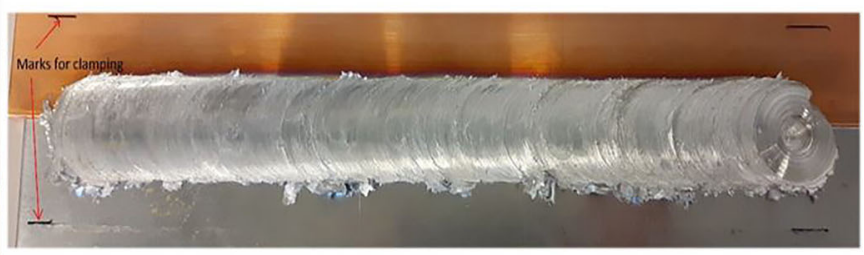

c)

and (4) side stoppers; (c) perspective of the top surface of the Al-Cu joint in as-welded condition

Welding conditions and parameters The equipment used for the FSW was an ESAB Legio 5, in position control mode, because preliminary tests demonstrated that it is difficult to maintain the stability and thus repeatability in long welds of dissimilar materials under force control mode. The tooling, clamping system, and resulting welds are represented in Fig. 5. The tool used for the welds was selected after preliminary tests. It has Ø24 mm concave shoulder and $\varnothing 8 \mathrm{~mm}$ LH-threaded taper 5.6- $\mathrm{mm}$ long probe (Fig. 5a). While some of the welding parameters were selected based on literature review and preliminary tests, namely, the rotation speed, tilt angle, and dwell time, other key process parameters, namely, the travel speed, weld position, and lateral offset position of the tool in relation to the joint line between the base materials were obtained via DoE [21]. Three performance parameters were used to optimize the selected key process parameters via the DoE: "global efficiency to tensile strength", see Eq. (1), "global efficiency to bending", see Eq. (2), for the mechanical properties and the "Electrical conductivity efficiency", see Eq. (4), for assessment of the electrical performance which is

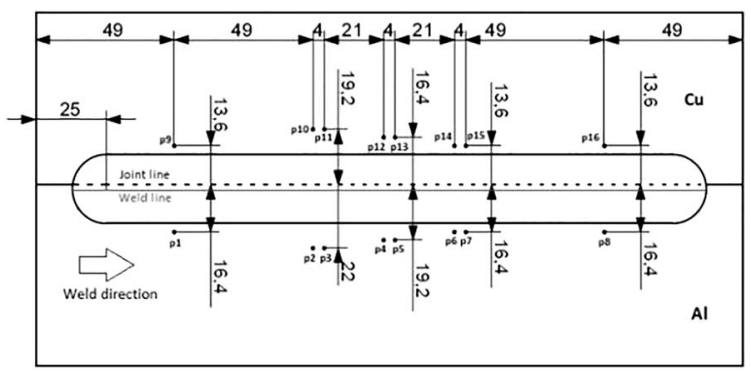

a)

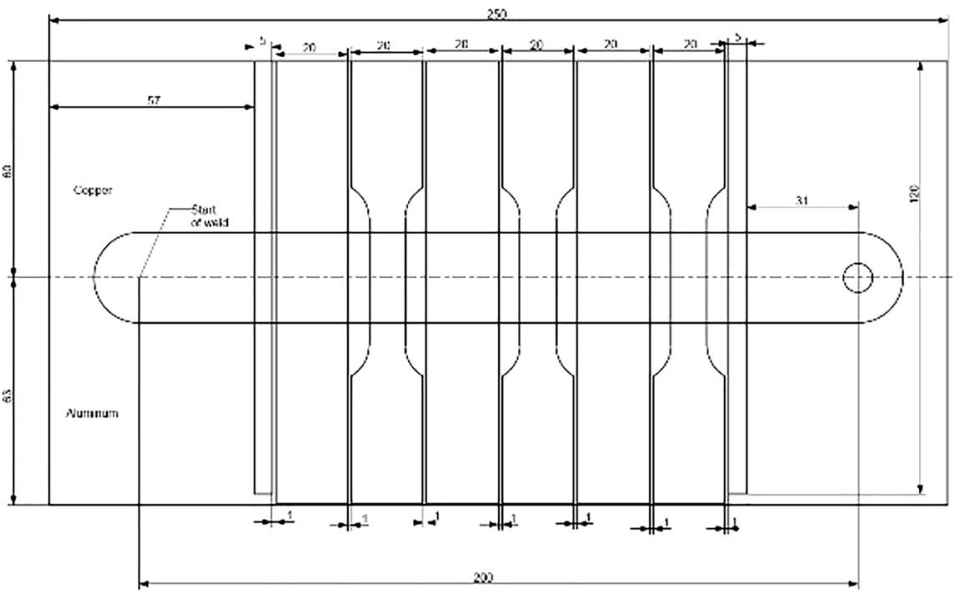

b)

Fig. 6 Schematic representation of some planned research actions of the weld joint properties: (a) plan of the thermocouple positions for temperature monitoring; (b) specimen extraction plan for metallurgical, mechanical, and electrical tests. Dimensions in millimeters 


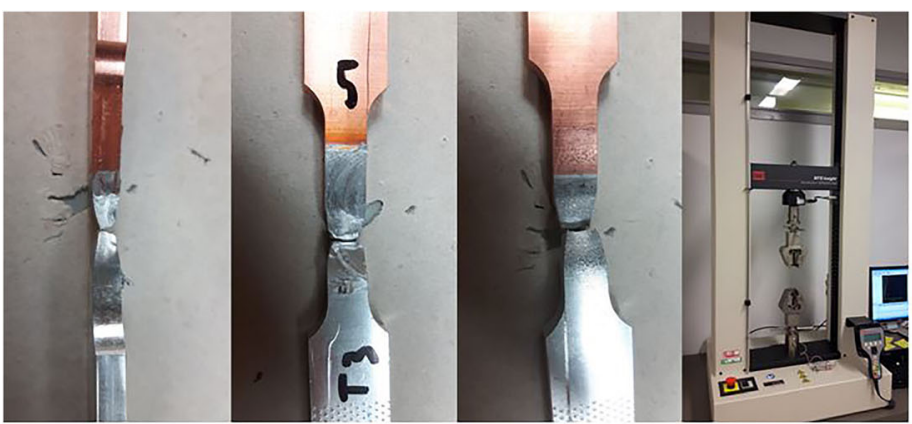

a)

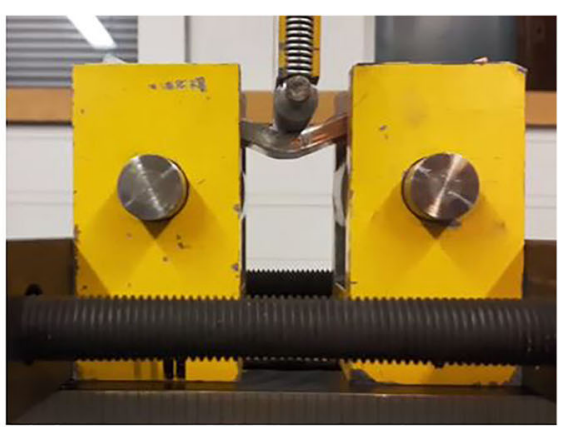

b)

Fig. 7 Mechanical testing of the welded Al-Cu specimens: (a) three specimens tested for tensile strength with fracture surface outside of the original joint line interface; (b) bending test operation

an important parameter in the design of busbars. The FSW parameters implemented for this weldability analysis were rotational speed $=800 \mathrm{rpm}(\mathrm{CW})$; travel speed $=125 \mathrm{~mm} / \mathrm{min}$; tool plunge position $=5.1 \mathrm{~mm}$ (leading to an average vertical forging force of about $9.5 \mathrm{kN}$ ); lateral offset into the $\mathrm{Al}$ side $=1.4 \mathrm{~mm}$ (revealed in the extraction hole of the tool probe in Fig. 5c); tilt angle $=2^{\circ}$; and dwell time $=5 \mathrm{~s}$. The $\mathrm{Cu}$ was placed on the advancing side of the welds as depicted in Fig. $5 \mathrm{~b}$.

The welds were produced with $200 \mathrm{~mm}$ in length, along the rolling direction of the $\mathrm{Al}-\mathrm{Cu}$ plates, starting and ending $25 \mathrm{~mm}$ away from the plate edges, as represented in Fig. 6. The specimens for bending, tensile, optical microscopy (OM), microhardness mapping, scanning electron microscopy (SEM), energy dispersive X-ray spectroscopy (EDS), and electrical resistance test specimen were extracted from the 200-mm long optimized AA1050-H14/24-Cu-OF-04 FSW welds.

Temperature monitoring Sixteen thermocouples K-type with $\varnothing 0.8 \mathrm{~mm}$ were positioned in drilled holes with $\varnothing 1.0 \mathrm{~mm}$ at mid-plate thickness depth, i.e., $3 \mathrm{~mm}$. Thermal paste was used for improved thermal conductivity and epoxy adhesive was applied to keep them stable. The thermocouples were positioned as represented in Fig. 6a. The strategical position was so that the thermocouples on each side were at same distance from the center of the stirred zone. The thermocouples were placed inside these holes. During the weld process, some of the thermocouples, especially on the $\mathrm{Al}$ side, were pushed away by the flash formed during the weld and their data is not considered for further evaluation (Fig. 9a, c).

Microstructural analysis Specimens for optical microscopy were polished using diamond paste down to $1 \mu \mathrm{m}$. Keller's solution was used for the etching of the $\mathrm{Al}$ side while the $\mathrm{Cu}$ was etched using $100 \mathrm{~mL}$ of distilled water, $4 \mathrm{~mL}$ of saturated sodium chloric, $2 \mathrm{~g}$ of potassium dichromate, and $5 \mathrm{~mL}$ sulfuric acid. Optical micrographs were made with a Nikon Epiphot 200 microscope. SEM was made using a Zeiss Ultra 55 field emission scanning electron microscope. EDS line analysis was done using the same equipment.

Hardness Microhardness measurements of a cross section of the weld were made using a CSM microcombi tester. Four hundred fifty-one indentations were made with an indentation load of $0.5 \mathrm{~N}$. The measurement matrix covered a $20 \mathrm{~mm}$ by $5 \mathrm{~mm}$ area containing the different weld zones and base materials present in the weld. The Oliver and Pharr [22] measurement method was used to determine the equivalent hardness Vickers of the indentations.

Mechanical testing (tensile and bending) The tensile tests were conducted using an MTS 858 Table Top System with resulting specimens presented in Fig. 7a. A $25 \mathrm{~mm}$

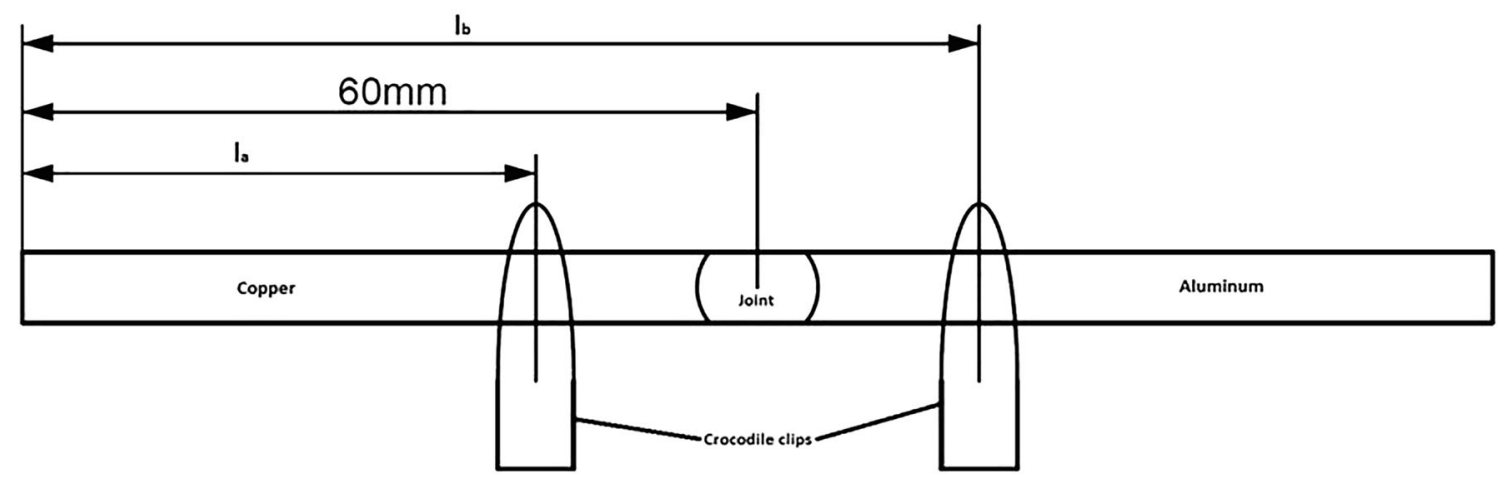

Fig. 8 Schematic representation of the electrical resistance measurement apparatus. Each of the specimens has a dimension of $5 \mathrm{~mm}($ width $) \times 6 \mathrm{~mm}$ (thickness) $\times 60 \mathrm{~mm}$ (length) 


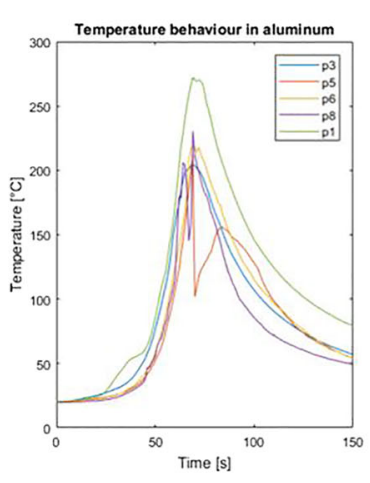

a)

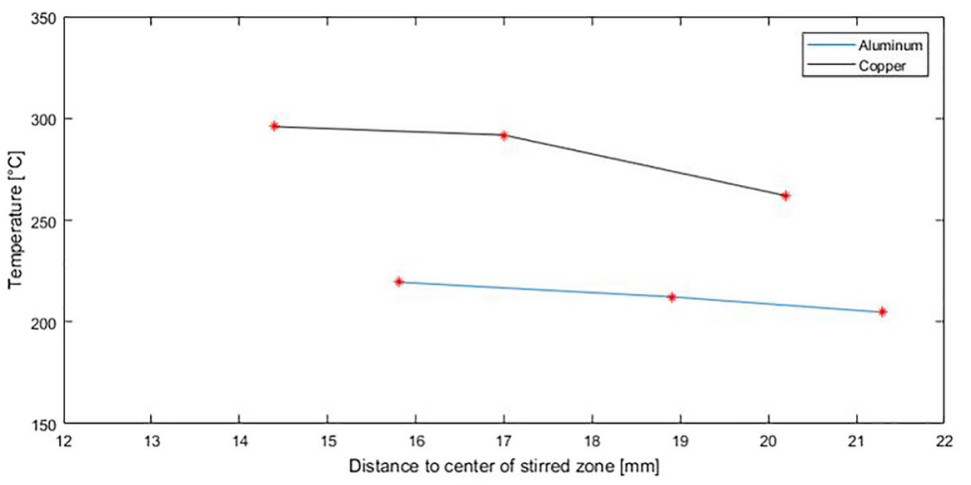

b)

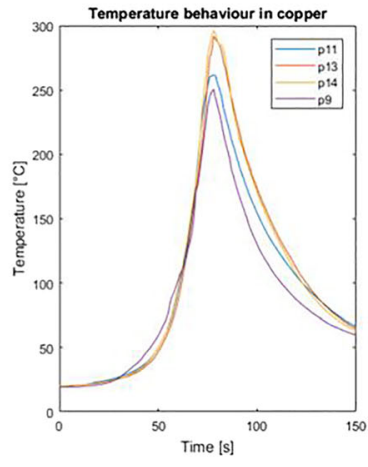

c)

Fig. 9 Temperature monitoring results: (a), (c) temperature history at the $\mathrm{Al}$ side and $\mathrm{Cu}$ side, respectively; (b) peak/maximum temperatures at different distances from the center of the stirred zone at both the $\mathrm{Al}$ side and $\mathrm{Cu}$ side

extensometer was used for registering the strain rate. Test speed for all tests was $1 \mathrm{~mm} / \mathrm{min}$. The bending test implemented was a 3-point bend testing as represented in Fig. 7b. Tests were made for each side of the weld seam under tensile load, root, and face, using an MTS 810 Material Test System at a constant speed of $10 \mathrm{~mm} / \mathrm{min}$. The distance between the supporting rollers was $78 \mathrm{~mm}$.

To assess the mechanical performance of the dissimilar Al$\mathrm{Cu}$ joints, two performance parameters were used: global efficiency to tensile strength (GETS), Eq. (1); and global efficiency to bending (GEB), Eq. (2). The GETS and GEB combine the ratio of the various tensile and bending properties of the weld zone to those of the base material [23]. In this work, the mechanical properties of the weld zone are compared to those of the AA1050-H14/24. The linear combination factors presented in Eqs. (1) and (2) were selected to put emphasis on the ductility of the joints over their strength and so the performance parameters are as follows:

$$
\begin{aligned}
\text { GETS }_{\text {weld }}= & 0.05 \frac{E_{\text {weld }}}{E_{B M}}+0.2 \frac{\sigma_{y_{\_} \text {weld }}}{\sigma_{y_{\_} B M}}+0.2 \frac{\sigma_{U T S_{-} \text {weld }}}{\sigma_{U T S_{-} B M}} \\
& +0.25 \frac{A_{\text {weld }}}{A_{B M}}+0.3 \frac{U_{T_{-} \text {weld }}}{U_{T \_B M}}
\end{aligned}
$$

$G E B_{\text {weld }}=0.4 \frac{F_{\text {weld }}}{F_{B M}}+0.3 \frac{d_{\text {weld }}}{d_{B M}}+0.3 \frac{U_{B \_ \text {weld }}}{U_{B \_B M}}$

where in the GETS, the $E$ is the Young modulus (based on Hooke Law $\sigma=k \varepsilon$ ); $\sigma_{y}$ is the yield true stress (offset of $0.2 \%$ ); $\sigma_{U T S}$ is the ultimate true stress; $A$ is the percent elongation at fracture in $50 \mathrm{~mm}$; and $U_{T}$ is the toughness $\left(U_{T}=\int_{\varepsilon_{0}}^{\varepsilon_{f}} \sigma d \varepsilon\right.$, determined based on approximation of stress-strain curve with rigid-plastic Ludwik Law: $\left.\sigma=k \varepsilon^{n}\right)$. True stress $(\sigma)$ and true strain $(\varepsilon)$ values are obtained from the engineering stress, $S=\frac{F}{A_{0}}$, and engineering strain $d \varepsilon=d l / l \Leftrightarrow \varepsilon=\ln (e+1)$ considering $\sigma=S(e+1)$ and $\varepsilon=\ln (e+1)$. And in GEB, the $F$ is the maximum load; $d$ is displacement at maximum load; and $U_{B}$ is the consumed energy (corresponding to the area below the $F$ versus $d$ graphic plot) until maximum load has been reached.

Electrical resistance testing The electrical resistance of the joint was measured and evaluated using a Cropico D07 microhmmeter. Resistance between two points on each side of the weld was measured and then the resistance contribution of the base materials subtracted to acquire the joint electrical resistance, $R_{\text {joint }}$, as established in Eq. (3) in according to formulation presented in [24]. See Fig. 8 for further clarification.

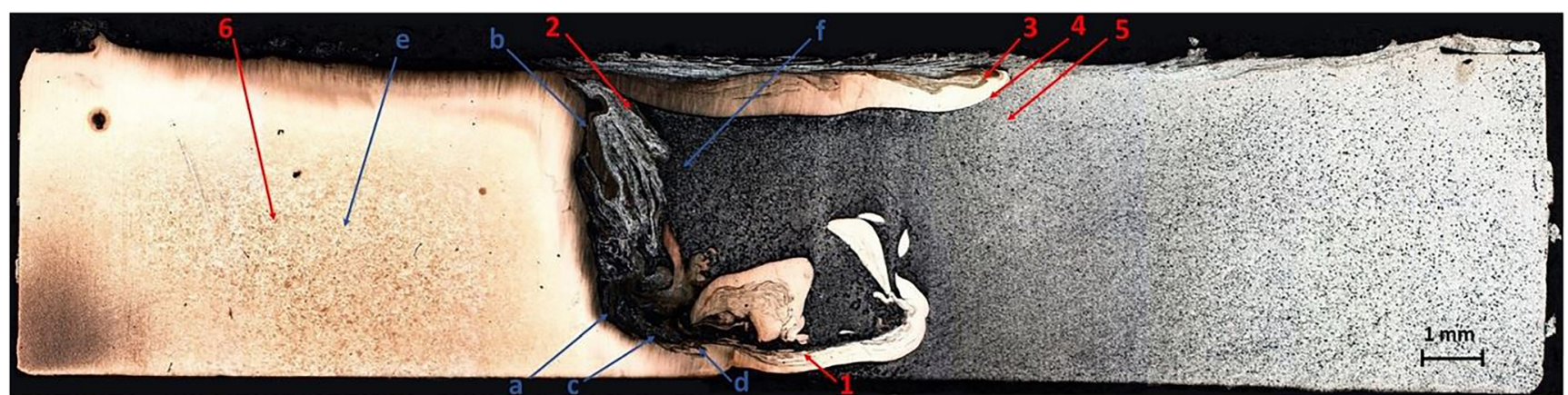

Fig. 10 Optical macrograph of the bimetallic FSW Al (right side and retreating side of the weld) $-\mathrm{Cu}$ (left side and advancing side of the weld) joint, with the areas marked from " 1 " to " 6 " detailed in the optical micrographs of Fig. 11 and areas marked from "a" to "f" detailed in the SEM micrographs of Fig. 12 


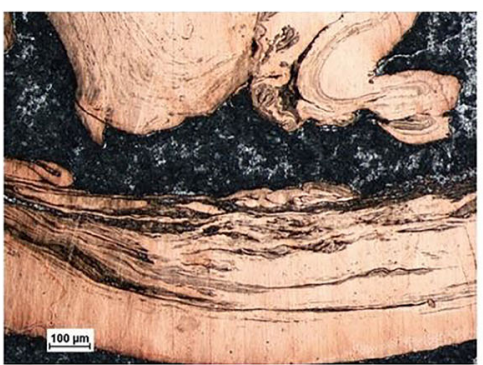

1)

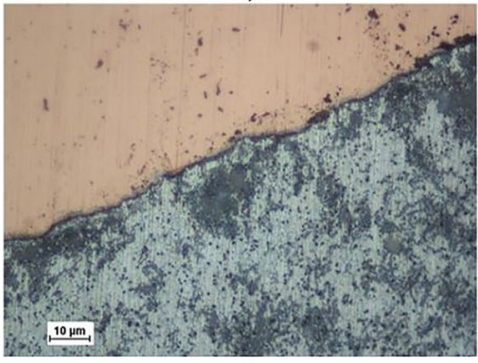

4)

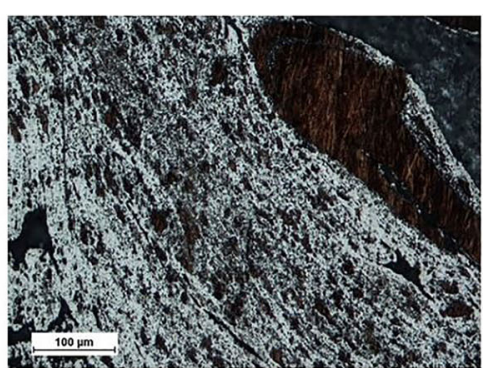

2)

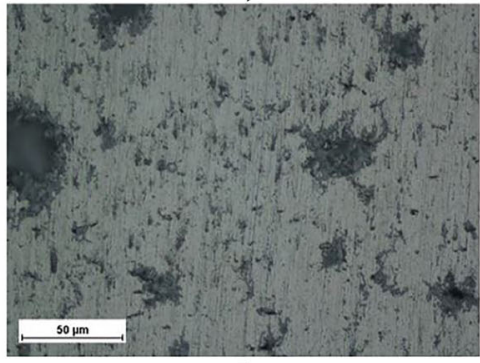

5)

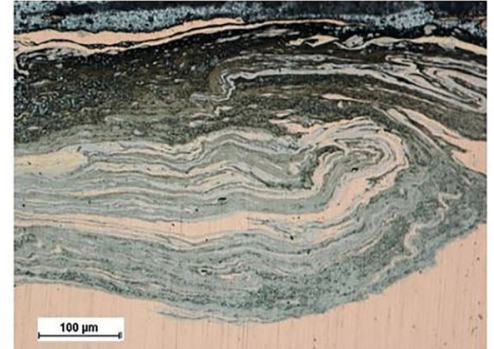

3)

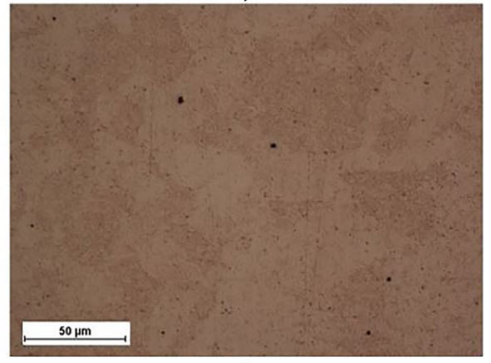

6)
Fig. 11 Optical micrographs of the joint in Fig. 10 from positions "1" to "6": (1) Cu-rich mixed material at the $\mathrm{Cu}$ "tongue" near the root of the weld joint; (2) intercalated lamellae structure; (3) multilayered structure at

The length of the electrical resistance specimens was $60 \mathrm{~mm}$, and their cross section was $5 \mathrm{~mm}$ (width, aligned with the RD) $\times 6 \mathrm{~mm}$ (thickness).

$R_{\text {Joint }}=R_{\text {Measured }}-\frac{\left(60-l_{a}\right) \rho_{C u}}{w_{C u} t_{C u}}-\frac{\left(l_{b}-60\right) \rho_{A l}}{w_{A l} t_{A l}}$

where $\rho_{C u}$ and $\rho_{A l}$ are the resistivity ( $\mu \Omega \mathrm{mm}$ ) of $\mathrm{Cu}$ and $\mathrm{Al}$, respectively; $l$ is the length as depicted in Fig. $8 ; w$ is the the $\mathrm{Cu}$ "tongue" near the face of the weld joint; (4) intermetallic layer; (5) microstructure at the heat-affected zone of the $\mathrm{Al} ;(6)$ microstructure at the heat-affected zone of the $\mathrm{Cu}$

width, and $t$ is the thickness of the cross section of the electrical resistance specimen.

To assess the performance of the dissimilar Al-Cu FSW joints, also the electrical conductivity efficiency $\left(\sigma_{\text {eff }}\right)$, as defined in the Eq. (4), based on the [24], was considered as a performance parameters.

$\sigma_{\text {eff }}=\frac{R_{A l}+R_{C u}}{R_{A l}+R_{C u}+R_{\text {Joint }}}$

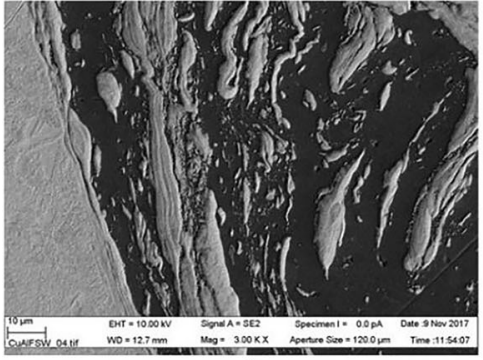

a)

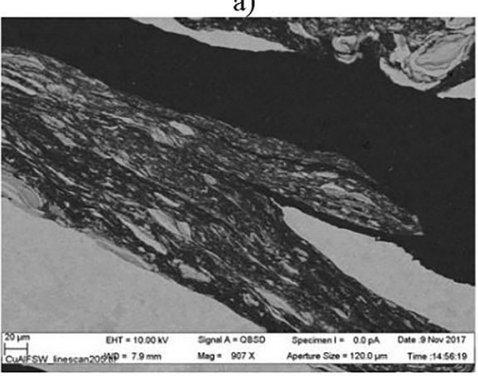

d)

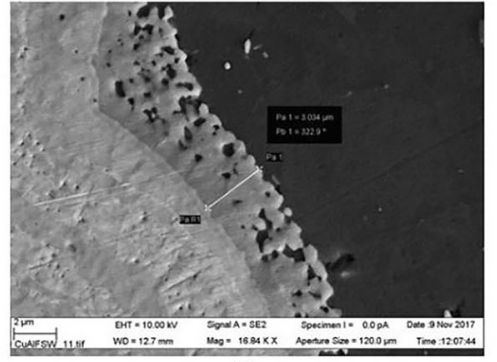

b)

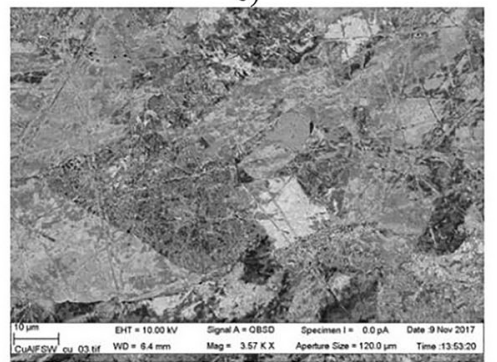

e)

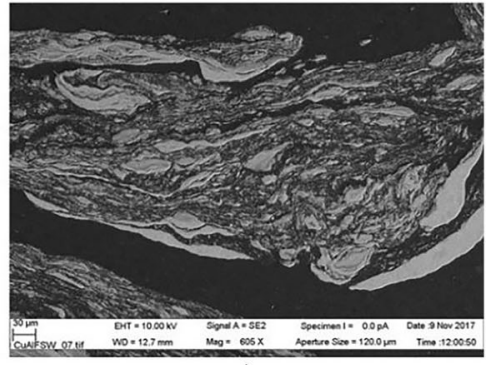

c)

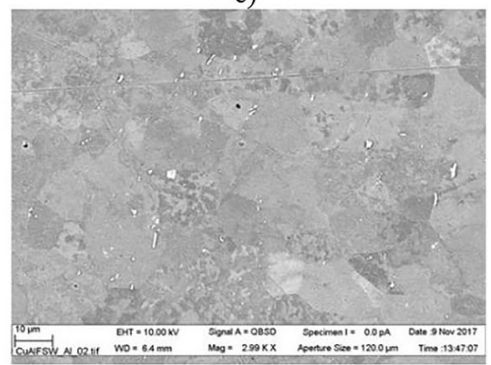

f)
Fig. 12 SEM micrographs of the joint in Fig. 10 from positions "a" to "f": (a) Al-based composite matrix; (b) IMC layer at the Al-Cu interface; (c) intercalated lamellae structure; (d) multilayered structure at the $\mathrm{Cu}$ "tongue" near the root of the weld joint; (e) microstructure at the heataffected zone of the $\mathrm{Cu}$; (f) $\mathrm{Al}$ microstructure with $\mathrm{Cu}$ particles in the stirred zone 

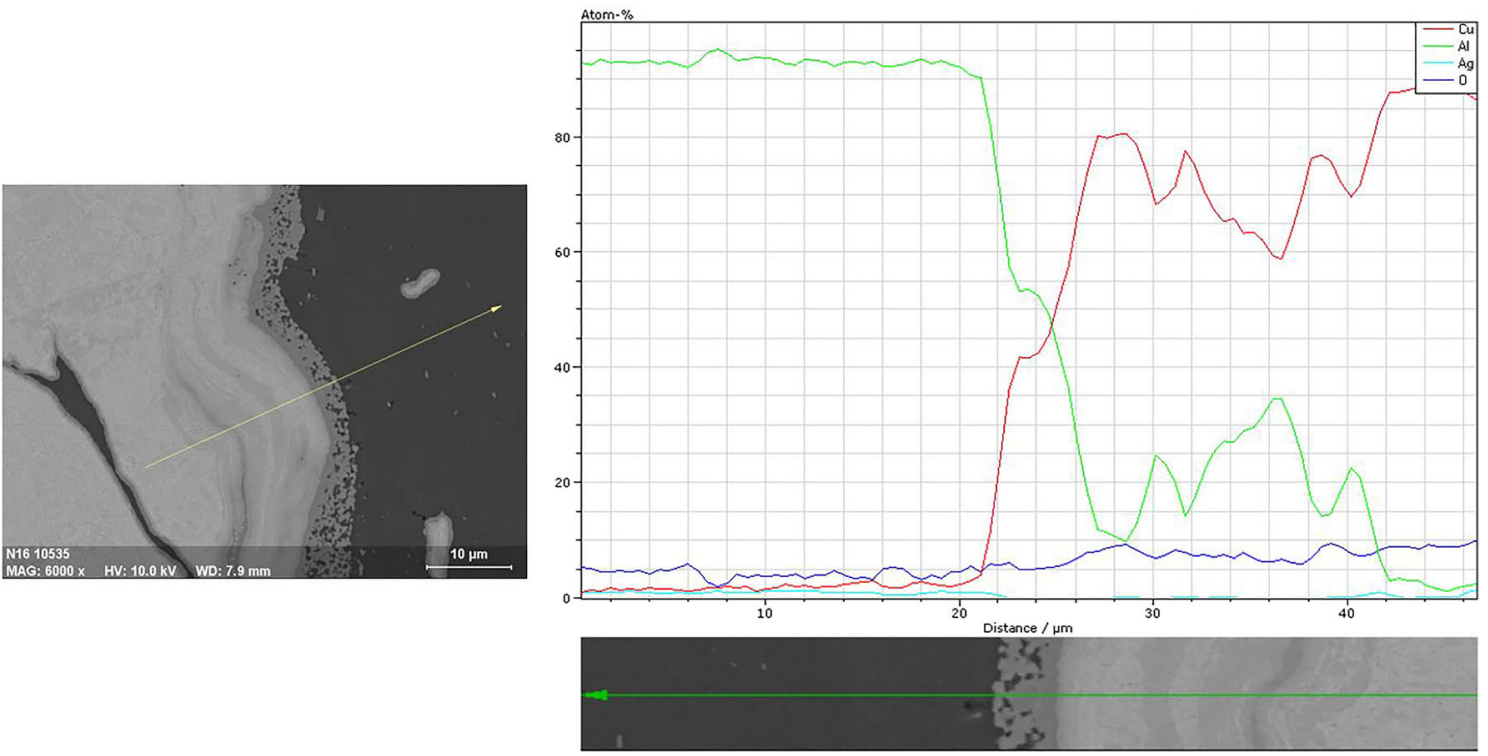

Fig. 13 EDS chemical composition analysis of the Al-Cu interface, presented in Fig. 12(b)

where $R_{A l}$ and $R_{C u}$ are the electrical resistances of the $\mathrm{Al}$ and $\mathrm{Cu}$, respectively, measured in a $12 \mathrm{~mm}$ long segment of each of the $\mathrm{Al}$ and $\mathrm{Cu}$ base materials, with $5 \mathrm{~mm}$ by $6 \mathrm{~mm}$ cross section.

The contact electrical resistance between the $\mathrm{Al}$ and $\mathrm{Cu}$ base materials was also measured with no weld joint, using different contact forces. This research action enables to compare it with the welded condition, and to evaluate the impact of the clamping force relaxation of bolted joints in the operation of the busbars. The $\mathrm{Al}$ and $\mathrm{Cu}$ base materials were cut into samples having the same
$5 \mathrm{~mm} \times 6 \mathrm{~mm}$ cross section as the weld specimens and their contacting ends were milled. Then they were clamped together using a vice and the electrical resistance over the contact measured for low, medium, and high forces. The lowest force was so that the samples would stay in place but could easily be moved by hand. Medium force was about $25 \mathrm{kN}$, the level of force measured at the end of the clamping force relaxation of bolted joints (Fig. 4). The high force was about $40 \mathrm{kN}$, corresponding to the considered maximum clamping force of bolted joints.
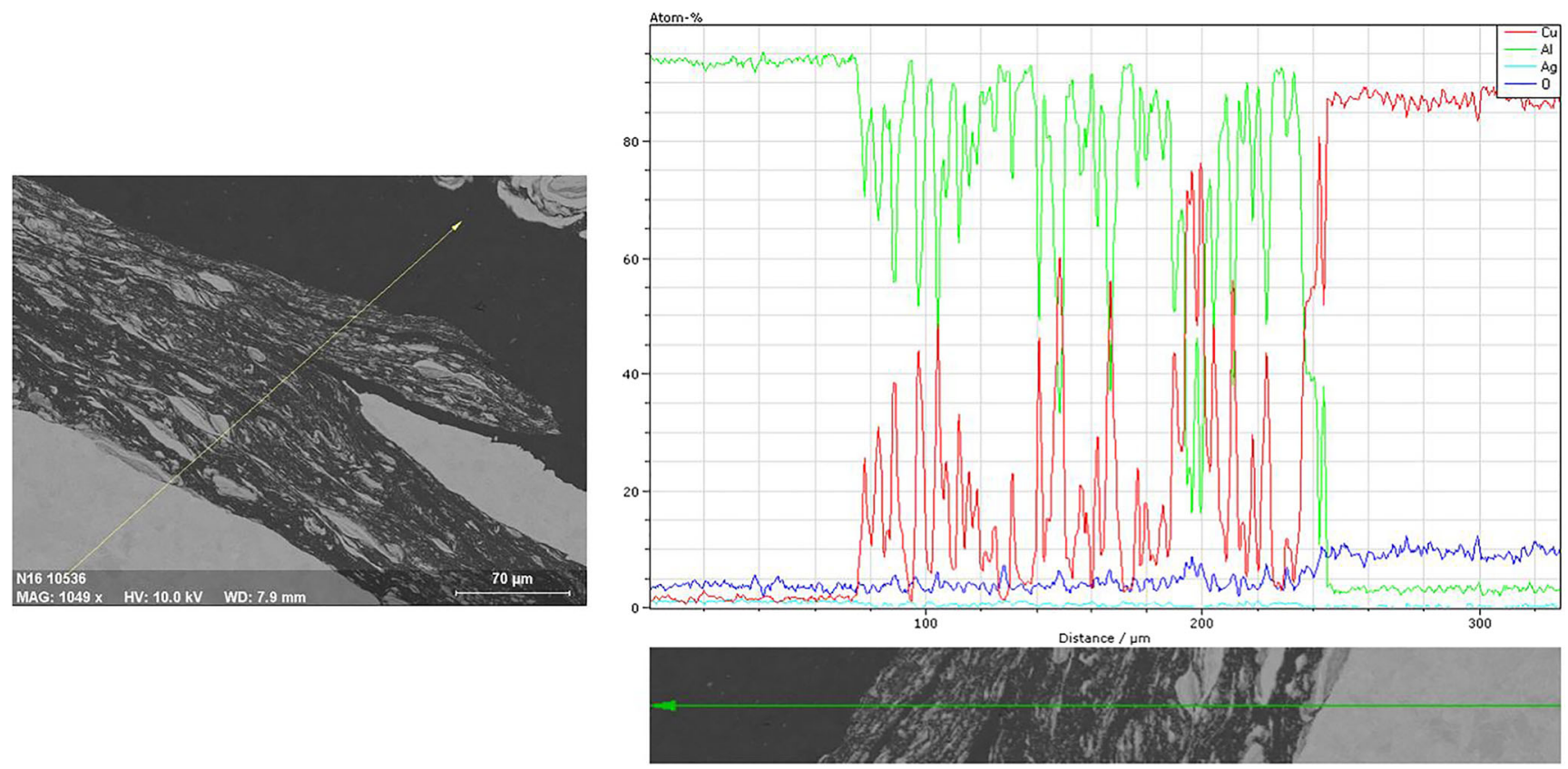

Fig. 14 EDS chemical composition analysis of the Al-Cu interface, presented in Fig. 12(d) 
Fig. 15 Microhardness field of the FSW joint cross section, with the optical macrograph transparent in the background. The indentation load applied was $0.5 \mathrm{~N}$

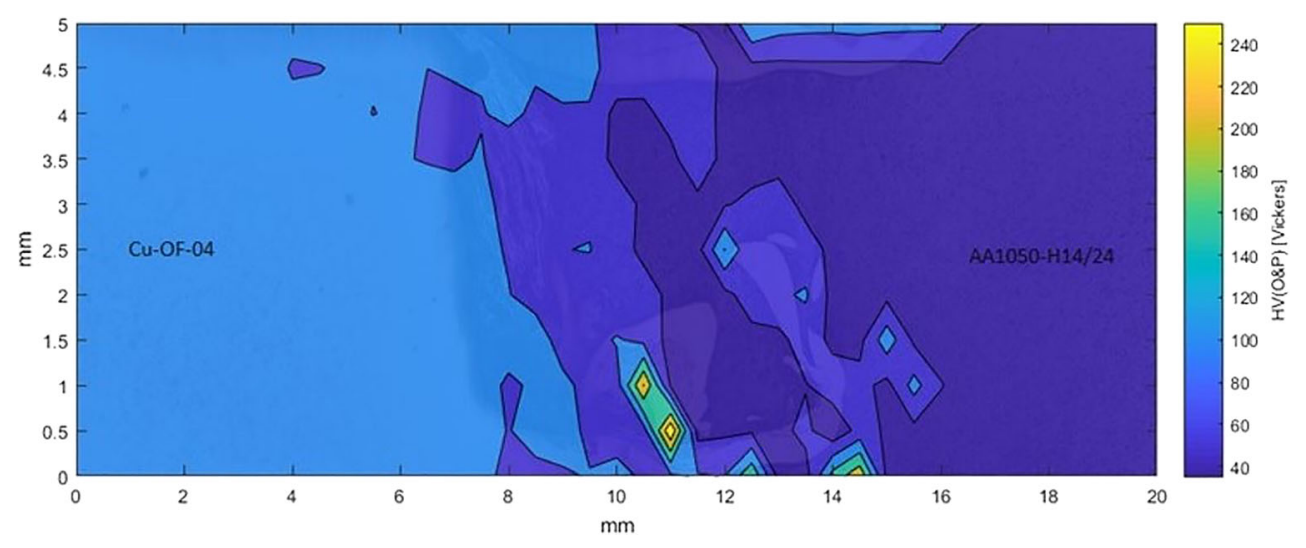

\section{Analysis of results}

\subsection{Temperature monitoring}

The monitoring of the temperature evolution in this bimetallic $\mathrm{Al}-\mathrm{Cu}$ joint contains relevant information on the scope of the fundaments of the heat generation in FSW. The temperature history of points at the same distance from the center of the stirred zone of the base materials differ during welding. The main facts are:

1. Most of the tool is over the Al plate, due to the lateral $1.4 \mathrm{~mm}$ offset into the Al side;

2. The maximum temperatures reached in the $\mathrm{Cu}$ side are significantly higher than in Al side, especially for the thermocouples closer to the center of the stirred zone. As an example, the maximum temperature in $\mathrm{Cu}$ at $15.8 \mathrm{~mm}$ distance from the center of the stirred zone is 293.7 ${ }^{\circ} \mathrm{C}$ while the maximum temperature in $\mathrm{Al}$ at the same distance from the stirred zone is $219.5^{\circ} \mathrm{C}$.

These facts emphasize that differently from what some authors consider in their heat generation models [4, 25], the bulk of the heat is not generated due to the friction dissipation at the sliding interfaces, but in the internal energy dissipation inherent to the viscoplastic deformation of the material flow imposed by the tool geometry. As a matter of fact emphasized by the present results, the heat generated in the $\mathrm{Cu}$ is significantly higher than the heat generated in the $\mathrm{Al}$, because for the $\mathrm{Cu}$ to reach the viscoplasticity, it dissipates more heat energy than the $\mathrm{Al}$, because the $\mathrm{Cu}$ toughness is higher than the $\mathrm{Al}$ toughness. Moreover, the higher conductivity of the $\mathrm{Cu}$ reduces this temperature difference, as it homogenizes the thermal gradient faster than the aluminum. So, the monitored temperature difference is even more relevant due to the difference in thermal conductivity.

The highest temperature reached in the Al side is at p1 (Fig. 9a), which is at the start of the weld. This is due to the pre-heat generated during the plunging and dwell period. Because travel speed has not started yet, and only tool rotation exists, with no significant material flow, the heat generated is mostly generated by interfacial sliding friction and axisymmetric. Also, the close vicinity of the edge of the plates does limit the heat losses. With the tool position offset used in the process, the probe is in more contact with the Al side and heats it up more than the $\mathrm{Cu}$ side at the start of the weld.

\subsection{Microstructure analysis: OM, SEM, and EDS}

The optical macrograph of the weld, presented in Fig. 10, shows the mixture of the original $\mathrm{Cu}$ and $\mathrm{Al}$ components, resulting from the stirring effect of the FSW tool. The layer of $\mathrm{Al}$ transported and left behind by the travelling and rotating tool shoulder, which is noticeable at the face of the weld in Fig. 5c, is very thin and overlaps a thicker $\mathrm{Cu}$ layer. The $\mathrm{Cu}$ involves the aluminum by two "tongues" near the face and root, in a quasi " $U$ " shape. Several regions with intercalated lamellae, diffusion, and formation of IMCs are possible to identify. The most interesting metallurgical regions, possible to identify in the optical macrograph, are selected to be depicted for analysis in optical micrographs (numbers 1 to 6 in Fig. 10) and SEM micrographs (letters $a$ to $f$ in Fig. 10), presented in Fig. 11 and Fig. 12, respectively.

Different $\mathrm{Al}-\mathrm{Cu}$ interaction patterns can be identified such as intercalated lamellae in Fig. 11(2) and Fig. 12(c). This morphology usually consists of two or more
Table 2 Tensile properties, with standard deviation, of the FSW joint, including the performance factor global efficiency to tensile strength (GETS)

\begin{tabular}{|c|c|c|c|c|c|}
\hline$E(\mathrm{GPa})$ & $\sigma_{\mathrm{y}}(\mathrm{MPa})$ & $\sigma_{\text {UTS }}(\mathrm{MPa})$ & $A(\%)$ & $U_{\mathrm{T}}\left(\mathrm{J} / \mathrm{mm}^{2}\right)$ & GETS \\
\hline $90.54 \pm 2$ & $64.09 \pm 2.9$ & $90.14 \pm 4.3$ & $26.80 \pm 4.8$ & $4.32 \pm 1.6$ & $0.85 \pm 0.1$ \\
\hline
\end{tabular}



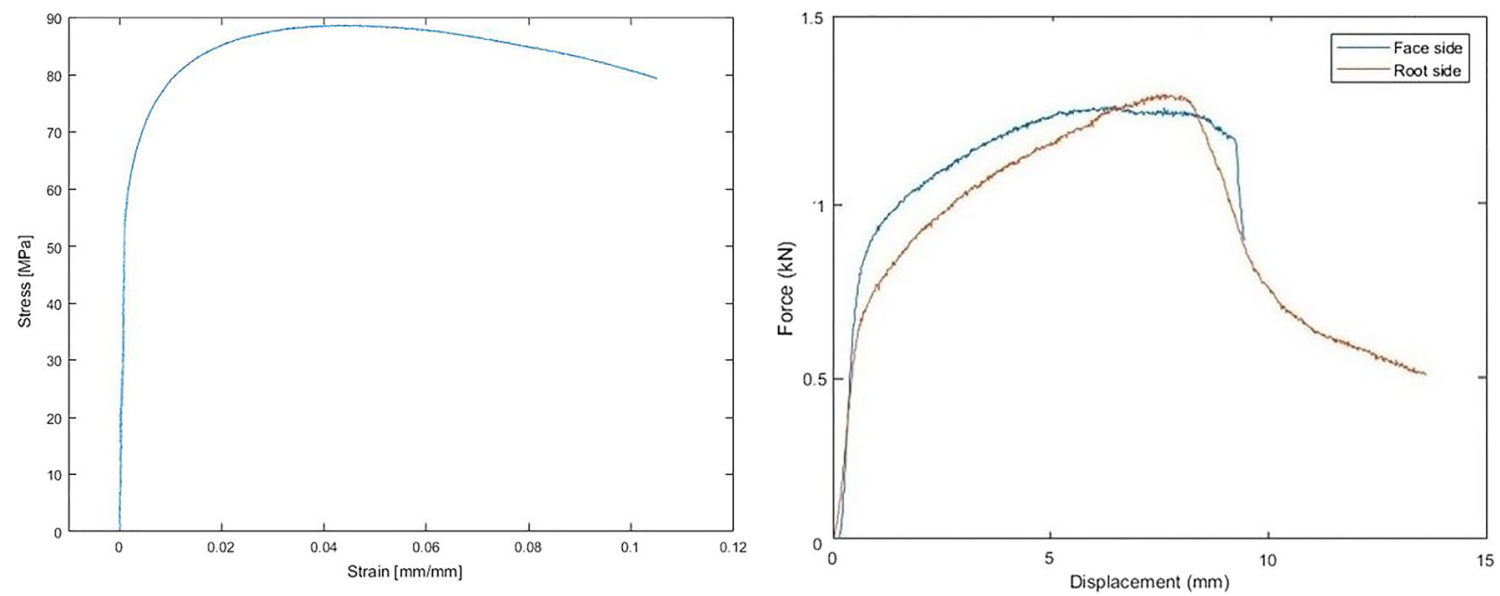

Fig. 16 Average results from the mechanical testing: (a) engineering stress-strain curves from the tensile test; (b) bending force-displacement curves from the 3-point bending tests with face and root under tensile stress condition

IMC phases and the formation is deeply influenced by process parameters such as rotational speed and lateral tool offset as reported by Galvão et al. [19] and Liu et al. [26]. Possible composite-like structures composed of $\mathrm{Cu}$, $\mathrm{Cu}$-rich, or IMC particles dispersed in an $\mathrm{Al}$ or Al-rich matrix are emphasized in Fig. 12(a). Interface layers of $\mathrm{Al}-\mathrm{Cu}$ are focused in Fig. 11(4) and Fig. 12(b). The darker gray layer next to the bulk Al in Fig. 12(b) was measured, and found to have a thickness of $6 \mu \mathrm{m}$.

The EDS was applied to the Al-Cu sample to investigate the mixing of materials in the weld-stirred zone, with corresponding chemical composition at some representative $\mathrm{Al}-\mathrm{Cu}$ interfaces. Fig. 13 and Fig. 14 present the chemical composition obtained with EDS line analysis of the $\mathrm{Al}-\mathrm{Cu}$ interface focused in Fig. $12 \mathrm{~b}$ and multilayered structure depicted in Fig. 12d, respectively. Efficient mixing and interlocking of $\mathrm{Cu}$ and $\mathrm{Al}$ is important to secure the mechanical strength of the weld. Uniform mixture of the metals improves also the heat transfer rate from the $\mathrm{Cu}$ plate to the channel. Possible gaps and non-mixed oxide layers reduce the resistance and electrical conductivity of the weld-stirred zone [16].

The evolution of the chemical composition obtained via $\mathrm{EDS}$, at two $\mathrm{Al}-\mathrm{Cu}$ interfaces with distinct patterns, is presented in Fig. 13 and 14. Based on the EDS, analysis is not possible to confirm the presence of IMC, but from the results of the chemical composition in Fig. 13, maybe $\mathrm{Cu}_{3} \mathrm{Al}_{2}$ ( $\delta$ ) and $\mathrm{Al}_{2} \mathrm{O}_{3}$ can be present. Also in Fig. 13, at the $\mathrm{Cu}$ base metal, from 28 to $42 \mu \mathrm{m}$, there is a solid solution of $\mathrm{Al}$ in $\mathrm{Cu}$, similar to the one also reported by Galvão et al. [27]. The line analysis in Fig. 14 depicts a mixed structure with multiple islands of $\mathrm{Al}$ and $\mathrm{Cu}$ along a distance from 70 to $250 \mu \mathrm{m}$. Thus, the multilayered structure at the $\mathrm{Cu}$ "tongue" near the root of the weld joint zone is well interlocked. The chemical composition changes in multilayered structure from $100 \% \mathrm{Al}$ to about $70 \% \mathrm{Cu}$. This indicates that the weld is potentially strong mechanically. Again, although the EDS analysis is not conclusive in the identification of IMC, considering the maximum solubility of $\mathrm{Al}$ in $\mathrm{Cu}$ of about $19.7 \%$ of at. content [28], the transition interface near the $\mathrm{Cu}$-rich zone may include the $\alpha$ phase peritectoid intermetallic compound $\mathrm{AlCu}_{4}$ (with at. $\mathrm{Cu}$ content of about $77 \%$ ).

\subsection{Hardness testing}

Figure 15 shows the clear difference in the hardness of the base materials, on each side of stirred zone. The $\mathrm{Cu}$ presents a microhardness of about $90 \mathrm{HV}$ while the Al presents microhardness around $40 \mathrm{HV}$. The stirred zone itself has a more complex distribution of hardness. $\mathrm{Cu}$ "tongues" near the face and the root and IMC particles, with higher hardness, enter the $\mathrm{Al}$ and result in the locally higher hardness fields within the softer Al. IMCs mostly localized at the bottom of the stirred zone cause the spikes in the microhardness seen there while the other mixed regions closer to the $\mathrm{Cu}$ have microhardness values in between that of the base materials.
Table 3 Bending properties of the FSW joint, with the root and the face of the weld joint under tensile condition, including the performance factor global efficiency to bending (GEB)

\begin{tabular}{cccccc}
\hline Side under tensile & $F_{\max }(\mathrm{kN})$ & $d_{@ \mathrm{Fmax}}(\mathrm{mm})$ & $U_{\mathrm{B}}\left(\mathrm{J} / \mathrm{mm}^{3}\right)$ & GEB & GEB $_{\text {average }}$ \\
\hline Face & 1.28 & 6.56 & 6.64 & 0.396 & $0.408 \pm 0.02$ \\
Root & 1.31 & 7.55 & 7.26 & 0.419 & \\
\hline
\end{tabular}


Table 4 Electrical resistance properties of the FSW joint versus a perfect electrical resistless joint

\begin{tabular}{lll}
\hline Joint resistance $(\mu \Omega)$ & Proportional increase $(\%)$ & бeff $(\%)$ \\
\hline $0.55 \pm 0.1$ & $2.9 \pm 5$ & $0.97 \pm 0.05$ \\
\hline
\end{tabular}

\subsection{Mechanical testing: tensile and bending loaded conditions}

A summary of the results from the tensile tests is presented in Table 2. The table shows an average performance of GETS $=85 \%$ corresponding to a stress-strain exhibited in Fig. 16a. The tensile specimens presented a relatively high elongation (26.8\%) with fracture at the $\mathrm{Al}$ side of the weld (Fig. 7a), in the heat-affected zone (HAZ).

There is small difference in the bending properties of the two sides of the joint, the root side being more efficient. The results from the bending tests show GEB as $41 \%$. Figure 16 displays the bending stress-strain curves from the bending tests made for both directions and the bending properties of the weld can be seen in Table 3 .

\subsection{Electrical resistance of the joint: welded and compressed not-welded conditions}

The joint resistance measured, and presented in Table 4, is very small compared to the contact resistance between $\mathrm{Al}$ and $\mathrm{Cu}$ in clamped joints, announced by other authors $[15$, 29]. This amount of resistance cannot be measured using normal electrical multimeters and is almost negligible as the resistance is only around 3\% higher than for a perfect electrical resistless joint. The FSW joint proved to be capable of transferring electricity with minimal to negligible power losses. To evaluate with precision under the same material and geometrical conditions, the contact electrical resistance between the same $6 \mathrm{~mm} \times 5 \mathrm{~mm}$ cross section surfaces of $\mathrm{Cu}-\mathrm{OF}-04$ and AA1050-H14/24 while subjected to various force levels was evaluated and presented in Table 5. The resistance of the FSW joint is 200 times lower than the contact resistance between the base materials while under an high clamping force, corresponding to the maximum clamping force of bolted joints (about $40 \mathrm{kN}$ ), considered in the evaluation of the clamping force relaxation presented in "Evaluation of the clamping force relaxation." Together, Table 1, Table 4, and Table 5

Table 5 Contact electrical resistance (without weld joint) between $6 \mathrm{~mm} \times 5 \mathrm{~mm}$ cross section surfaces of $\mathrm{Cu}-\mathrm{OF}-04$ and AA1050-H14/ 24 while subjected to various compressive contact force levels

\begin{tabular}{ll}
\hline Contact force (levels) & Contact resistance $(\mu \Omega)$ \\
\hline$\sim 5 \mathrm{~N}$ (low) & $8000 \pm 2000$ \\
$\sim 25 \mathrm{kN}$ (medium) & $340 \pm 30$ \\
$\sim 40 \mathrm{kN}$ (high) & $110 \pm 30$ \\
\hline
\end{tabular}

emphasizes the significant operational benefit of Al busbar with FSWelded $\mathrm{Cu}$ ends. This is a fact because the contact resistance increases significantly with the drop of the clamping force (e.g., about three times from 40 to $25 \mathrm{kN}$ of clamping force drop), and the $\mathrm{Al}$ ends present a significantly higher rate of relaxation of the clamping force compared with the $\mathrm{Cu}$ ends (e.g., two times faster for $\Delta \mathrm{F} /$ cycle@100-200 first thermal cycles).

\section{Conclusions}

The investigation of the bimetallic FSW joint between the plates with thickness of $6 \mathrm{~mm}$, made of AA1050-H14/24 and $\mathrm{Cu}-\mathrm{OF}-04 \mathrm{FSW}$, with the manufacturing of $\mathrm{Al}$ busbar with welded $\mathrm{Cu}$ ends in mind, delivered the following main results:

- The monitoring of the temperature disclosed that even though most of the tool is over the Al plate, due to the lateral $1.4 \mathrm{~mm}$ offset into the $\mathrm{Al}$ side, the maximum temperatures reached in the $\mathrm{Cu}$ side are significantly higher than in $\mathrm{Al}$ side. For example, at $15.8 \mathrm{~mm}$ distance from the center of the stirred zone, maximum temperature in $\mathrm{Cu}$ is $293.7^{\circ} \mathrm{C}$, while the maximum temperature in $\mathrm{Al}$ is 219.5 ${ }^{\circ} \mathrm{C}$. These facts emphasize that the bulk of the heat is not generated due to the friction dissipation at the sliding interfaces, but in the internal energy dissipation inherent to the viscoplastic deformation of the material flow imposed by the tool geometry;

- Metallurgical investigation of the joints shows an intense mixture of materials with large amounts of multilayered structures, both Al-matrix composite and intercalated lamellae. The $\mathrm{Cu}$ involves the aluminum by two "tongues" near the face and root, in a quasi "U" shape. Most of these microstructural features are possible to identify in the pattern of the hardness field;

- In terms of mechanical properties compared to the $\mathrm{Al}$ component, the efficiency to tensile strength was $85 \%$, and efficiency to bending was $41 \%$;

- FSW joints produced show a negligible electrical resistance compared to the resistance between clamped base materials. The electrical resistance of the FSW joint is 200 times lower than the contact resistance between the base materials while under the highest tested clamping force, of about $40 \mathrm{kN}$;

- A significant operational benefit of Al busbar with FSWelded $\mathrm{Cu}$ ends was proved. The electrical contact resistance increases significantly with the drop of the clamping force and the $\mathrm{Al}$ ends present a significantly higher rate of relaxation of the clamping force compared with the $\mathrm{Cu}$ ends, e.g., two times faster for $\Delta \mathrm{F} / \mathrm{cy}$ cle@100-200 first thermal cycles. 
Acknowledgements Open access funding provided by Aalto University.

Open Access This article is distributed under the terms of the Creative Commons Attribution 4.0 International License (http:// creativecommons.org/licenses/by/4.0/), which permits unrestricted use, distribution, and reproduction in any medium, provided you give appropriate credit to the original author(s) and the source, provide a link to the Creative Commons license, and indicate if changes were made.

\section{References}

1. Thomas W (1991) "“Friction stir butt welding,"” International Patent Application no.PCT/GB92/0220.

2. Lohwasser D, Chen Z (2009) Friction stir welding: from basics to applications. Elsevier, Amsterdam

3. Mishra RS, De PS, Kumar N (2014) Friction stir welding and processing: science and engineering. Springer, Amsterdam

4. Schmidt HB, Hattel JH (2008) Thermal modelling of friction stir welding. Scr Mater 58(5):332-337

5. Murugan B, Thirunavukarasu G, Kundu S, Kailas SV, Chatterjee S (2018) Interfacial microstructure and mechanical properties of friction stir welded joints of commercially pure aluminum and 304 stainless steel. J Mater Eng Perform 27(6):2921-2931

6. Shen Z, Chen Y, Haghshenas M, Gerlich A (2015) Role of welding parameters on interfacial bonding in dissimilar steel/aluminum friction stir welds. Engineering Science and Technology, an International Journal 18(2):270-277

7. Sorger G, Wang H, Vilaça P, Santos TG (2017) FSW of aluminum AA5754 to steel DX54 with innovative overlap joint. Weld. World 61(2):257-268

8. Mehta KP, Badheka VJ (2016) A review on dissimilar friction stir welding of copper to aluminum: process, properties, and variants. Mater Manuf Process 31(3):233-254

9. Vilaça P, Mendes J, Nascimento F, Quintino L (2016) Application of FSW to join aluminium foil winding coils for electrical transformers. Int J Mech Syst Eng 2(1):115-111

10. Pruitt BL, Park W, Kenny TW (2004) Measurement system for low force and small displacement contacts. J Microelectromech Syst 13(2):220-229

11. Sullivan CR (2008) Aluminum windings and other strategies for high-frequency magnetics design in an era of high copper and energy costs. IEEE Trans Power Electron 23(4):2044-2051

12. W. S. Loewenthal and D. L. Ellis, "“Fabrication of GRCop-84 rocket thrust chambers,"” 2005.

13. Davis JR, Davis JR (1993) Aluminum and aluminum alloys. ASM international, Cleveland

14. Nix F, MacNair D (1941) The thermal expansion of pure metals: copper, gold, aluminum, nickel, and iron. Phys Rev 60(8):597
15. Jackson R (1982) Electrical performance of aluminium/copper bolted joints. In: IEE Proceedings $\mathrm{C}$ (Generation, Transmission and Distribution), pp 177-184

16. Napieralska-Juszczak E, Komeza K, Morganti F, Sykulski JK, Vega G, Zeroukhi Y (2017) Measurement of contact resistance for copper and aluminium conductors. Int J Appl Electromagn Mech 53(4): 617-629

17. DebRoy T, Bhadeshia H (2010) Friction stir welding of dissimilar alloys-a perspective. Science and Technology of Welding and Joining 15(4):266-270

18. Schulze GE (2013) Metallphysik: Ein Lehrbuch. Springer-Verlag, Berlin

19. Galvao I, Oliveira J, Loureiro A, Rodrigues D (2011) Formation and distribution of brittle structures in friction stir welding of aluminium and copper: influence of process parameters. Science and Technology of Welding and Joining 16(8):681-689

20. Khodir S, Ahmed M, Ahmed E, Mohamed SM, Abdel-Aleem H (2016) Effect of intermetallic compound phases on the mechanical properties of the dissimilar $\mathrm{Al} / \mathrm{Cu}$ friction stir welded joints. Journal of Materials Engineering and Performance 25(11):4637-4648

21. Ólafsson D (2017) "“Friction stir welding of aluminum - copper"”. Aalto Master thesis.

22. Oliver WC, Pharr GM (1992) An improved technique for determining hardness and elastic modulus using load and displacement sensing indentation experiments. J Mater Res 7(6):1564-1583

23. Vilaça P, Thomas W (2011) Friction stir welding technology. In: Structural Connections for Lightweight Metallic Structures. Springer, Berlin, pp 85-124

24. Farrell T (2012) Chapter 2 - Measurement techniques. In: The Handbook of electrical resistivity: new materials and pressure effects by G. Dyos, The institution of Engineering and Technology, pp 11-24

25. Neto DM, Neto P (2013) Numerical modeling of friction stir welding process: a literature review. The International Journal of Advanced Manufacturing Technology 65(1-4):115-126

26. Liu HJ, Shen JJ, Xie S, Huang YX, Cui F, Liu C, Kuang LY (2012) Weld appearance and microstructural characteristics of friction stir butt barrier welded joints of aluminium alloy to copper. Science and Technology of Welding and Joining 17(2):104-110, February 01

27. Galvão I, Loureiro A, Rodrigues DM (2016) Critical review on friction stir welding of aluminium to copper. Science and Technology of Welding and Joining 21(7):523-546, October 02

28. Murray JL (1985) The aluminium-copper system. International Metals Reviews. 30(1):211-233

29. Bonwitt W (1948) An experimental investigation of the electrical performance of bolted aluminum-to-copper connections. Transactions of the American Institute of Electrical Engineers 67(2):1208-1219

Publisher's note Springer Nature remains neutral with regard to jurisdictional claims in published maps and institutional affiliations. 